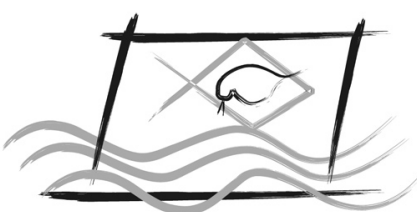

ECOTOX - BRASIL

\title{
Validação dos Bioensaios de Toxicidade como Adjuvantes no Monitoramento de Efluentes para Descarte
}

\author{
C.C. De Sousa ${ }^{1}$; L. Padula ${ }^{2} ;$ L.F. Silva ${ }^{2} \&$ S.P. Irazusta ${ }^{2,3}$ \\ ${ }^{1}$ Mestre em Tecnologia pelo Centro Estadual de Educação Tecnológica Paula Souza, São Paulo, São Paulo \\ ${ }^{2}$ Faculdade de Tecnologia de Sorocaba -FATEC-So \\ ${ }^{3}$ Programa de Mestrado em Tecnologia: Gestão, Desenvolvimento e Formação - Centro Estadual de Educação Tecnológica Paula Souza, \\ São Paulo, São Paulo
}

(Received October 21, 2011; Accept December 18, 2012)

\begin{abstract}
Toxicity Bioassay Validation as a Support for Monitoring Effluent Discharge - The present work aimed evaluating the impact of precipitation with sodium hydroxide and sodium sulfide, that clearly reduce the chemical contaminants of the effluent, leading to toxicity reduction. Metal analysis by ICP/AES (Inductively Coupled Plasma/Atomic Emission Spectroscopy), physicochemical analysis $(\mathrm{pH})$ and toxicological analysis (by measuring the production of micronuclei in Allium cepa) were performed in the effluent studied before and after the precipitation. The analysis before treatment showed the extreme acidity of the effluent $(\mathrm{pH}<1,0)$, metals above the acceptable level for discharging according to the standards (especially zinc and iron) and significant mutagenicity. After precipitation with sodium sulfide, there was enough reduction in metals concentration to allow the effluent discharging within the limits specified by Conama Resolutions 357/2005 and 430/2011, and with both precipitants the discharging was possible according to the limits specified by 8468/76 Decree (São Paulo State/Brazil) (for the elements studied). There was also significant reduction in mutagenicity after treatment. The use of mutagenicity bioassay with $A$. cepa as a supplementary protocol to the ones already recommended for effluent analysis is emphasized in the present work.
\end{abstract}

Keywords: Allium cepa, laboratory effluent, heavy metals, mutagenicity.

\section{INTRODUÇ̃̃O}

Os protocolos de ensaios biológicos (testes de toxicidade aguda e de genotoxicidade/mutagenicidade) são obrigatórios para descargas de efluentes em alguns países, enquanto que em outros, somente as características físicas e químicas são necessárias (Bertoletti, 1990; Kim et al., 2008). Baixos níveis de toxicidade aguda são detectados em efluentes que são descartados, mesmo após um eficiente tratamento secundário (Dizer et al., 2002). Por estarem os agentes tóxicos quase sempre em concentrações muito reduzidas ou serem de caráter químico desconhecido, os biotestes para monitoração poderiam ser bastante úteis (Pessala et al., 2004).
Os ensaios de toxicidade constituem uma forma de biomonitoração ativa, pois neles são utilizados organismosteste, definidos como indivíduos padronizados e cultivados em laboratório, que podem fornecer indicações sobre as condições de um ecossistema frente à presença de impacto ambiental (RayaRodriguez, 2000). Sua utilização fundamenta-se na exposição dos organismos-teste a várias concentrações de uma ou mais substâncias, ou fatores ambientais, durante um determinado período de tempo (Gherardi-Goldstein et al., 1990).

Não existem parâmetros previstos em normas para a toxicidade de efluentes laboratoriais, como existem para os parâmetros químicos e físico-químicos individuais. A análise dos efeitos tóxicos de uma amostra sobre um organismo permite contemplar a interação de seus componentes

*Corresponding author: C. C. de Sousa; e-mail: criscampos@1ycos.com 
individuais em mistura. Radić et al. (2010) apontam que testes para verificação da presença de substâncias mutagênicas em misturas complexas (tais como efluentes industriais) são cada vez mais aceitos como métodos rotineiros em programas de monitoração ambiental e sugerem que ensaios de toxicidade/ mutagenicidade sejam incluídos nestes programas, juntamente com análises químicas convencionais.

A poluição por metais pesados sempre foi um dos mais importantes problemas ambientais (Matsumoto et al., 2006; Zaki et al., 2007; Abo-Farha et al., 2009; Wang \& Chen, 2009; Chatterjee et al., 2010), já que os íons de metais pesados são estáveis como contaminantes ambientais persistentes, não sendo degradados e/ou destruídos (Abo-Farha et al., 2009). Estes íons metálicos podem ser prejudiciais à vida aquática e causar grave poluição de solo (Lin \& Juang, 2002). É bem estabelecida a relação entre metais e uma variedade de respostas tóxicas em humanos (Gaballah \& Kilbertus, 1998; Franchi, 2004; Nascimento et al., 2006; Abo-Farha et al., 2009). Esta complexidade dos constituintes torna difícil a determinação de riscos ambientais unicamente por meio de análises químicas.

El-Shahaby et al. (2003), analisaram efluentes industriais em um rio, com amostras colhidas a montante e a jusante das descargas. Seus resultados apresentaram provas de que as amostras de água eram altamente mutagênicas, correlacionando-se parcialmente com as determinações de metais pesados nestas amostras. Outro estudo utilizando como biomarcadores sementes de Greviella exul var. rubiginosa demonstrou que a presença de metais pesados, como o níquel (em especial o cloreto de níquel), é capaz de inibir a germinação e o crescimento das raízes, além de comprometer a absorção dos macronutrientes (Léon et al., 2005).

Desta forma, técnicas de citogenética, anormalidades do núcleo celular como binúcleo e micronúcleo são considerados bons indicadores de citotoxicidade e mutagenicidade, respectivamente. Por esta razão, o uso de organismos sentinela para monitoramento biológico poderia providenciar uma estimativa fidedigna dos efeitos potenciais de poluentes. Biomonitores como a espécie Allium cepa L., têm sido usados para alertar a população sobre contaminação ambiental e emissões químicas genotóxicas. Os impactos causados por agentes tóxicos no meio ambiente e no homem, geralmente não podem ser observados ou medidos diretamente e informações obtidas por biomonitores permitem estimar e comparar estes impactos (Bagatini et al., 2009). O teste de toxicidade aguda e mutagenicidade com Allium cepa é bastante antigo, foi introduzido por Levan em 1938 e proposto como método padrão em monitorização ambiental e de triagem para efluentes e rios (Fiskesjö, 1993; Rank, 2003). Trata-se de um teste de baixo custo, simples, e fornece boa correlação com ensaios em mamíferos (Fiskesjö, 1985).

Entre os vegetais superiores, a planta Allium cepa tem sido indicada como um eficiente organismo-teste de citotoxicidade e genotoxicidade devido a determinadas características, como sua cinética de proliferação, crescimento rápido de suas raízes, grande número de células em divisão, sua alta tolerância a diferentes condições de cultivo, sua disponibilidade durante o ano todo, seu fácil manuseio e por possuir cromossomos em número reduzido e de grande tamanho (Fiskesjö, 1985; Grant, 1994) e seu baixo custo (Leme \& Marin-Morales, 2009). Esta espécie tem sido utilizada, com sucesso, na avaliação de químicos, sendo eles substâncias puras ou misturas complexas, como é o caso de grande parte das amostras ambientais (Fiskesjö, 1985; Ma et al., 1995; Leme \& Marin-Morales, 2009; Mazzeo et al., 2010).

Entre os métodos utilizados para redução da carga química, a precipitação/coagulação constitui o tratamento de efluente mais antigo ainda em uso hoje e suas vantagens são muitas. Este método simples e normalmente barato é fácil de ser instalado em plantas de tratamento e sua operação é direta. A precipitação/coagulação permite a eliminação de sólidos em suspensão, matéria orgânica e muitos outros contaminantes (Janin et al., 2009). Como muitos metais formam sais insolúveis quando reagem com hidróxido, sulfeto ou carbonato, a técnica de precipitação é o método mais simples empregado para tratamento de efluentes, quando o objetivo é a remoção de metais (Kramer \& Allen, 1988). Na precipitação alcalina convencional, o objetivo é adaptar o $\mathrm{pH}$ para transformação do metal dissolvido em material insolúvel (Huisman et al., 2006).

Com base nestes processos e mediante a necessidade de se propor uma estratégia de manejo adequado ao efluente gerado em um laboratório de prestação de serviços na área química, o objetivo deste trabalho foi avaliar o desempenho do hidróxido de sódio $(\mathrm{NaOH})$ e do sulfeto de sódio $\left(\mathrm{Na}_{2} \mathrm{~S}\right)$ na remoção de metais deste efluente, e o impacto desta redução em seu potencial mutagênico. A proposta do ensaio de mutagenicidade com A. cepa como protocolo suplementar aos já regulamentados para análise de efluentes para descarte, é enfatizada neste trabalho.

\section{MATERIAIS E MÉTODOS}

\section{Caracterização do Efluente}

O primeiro passo para este estudo foi a caracterização do efluente produzido em um laboratório de análises de composição de ligas metálicas. Para isso foi coletado todo o efluente produzido durante um período de sete meses (de outubro de 2008 a abril de 2009), para verificação do volume gerado. Além disso, foram realizadas análises químicas mês a mês para quantificação dos metais por meio de leitura direta em ICP/AES - Espectrometria de Emissão Atômica/Plasma Acoplado Indutivamente, marca Spectro, modelo Spectroflame além da determinação de $\mathrm{pH}$ em pHmetro Micronal, modelo B474.

$\mathrm{O}$ efluente produzido diariamente foi armazenado durante um mês em um frasco e refrigerado (dispensando a preservação com ácido nítrico recomendada pelo método (Eaton et al., 2005) por se tratarem de amostras provenientes de ligas metálicas tratadas com ácido clorídrico e nítrico). Ao final do mês realizou-se a determinação do volume produzido no período, a leitura de $\mathrm{pH}$ e a determinação de metais. 
Em relação ao $\mathrm{pH}$, a temperatura de $20^{\circ} \mathrm{C}$ foi escolhida por ser a temperatura mais próxima à do ambiente do laboratório.

Os metais quantificados foram: prata, cromo, cobre, ferro, níquel, chumbo, estanho e zinco. A escolha destes elementos se deveu ao fato de terem suas emissões controladas pelo Decreto 8.468/76 (São Paulo/BR, 1976) e Resoluções Conama 357/2005 e 430/2011 e também por se tratarem dos elementos mais frequentemente encontrados nas ligas analisadas pelo laboratório em estudo.

A metodologia analítica para determinação dos metais e do $\mathrm{pH}$ atendeu às especificações do Standard Methods for the Examination of Water and Wastewater de autoria das instituições APHA (American Public Health Association), AWWA (American Water Works Association) e WEF (Water Environment Federation) (Eaton et al., 2005). Para as análises toxicológicas, foi seguido o protocolo de Ma et al. (1995) com modificações.

\section{Bioensaio de Mutagenicidade}

Após a caracterização, foi coletado um novo efluente (representativo da coleta de um mês de trabalho) para que os tratamentos com hidróxido de sódio e sulfeto de sódio fossem aplicados.

Parte deste efluente $(500 \mathrm{~mL})$ foi utilizado para verificação da eficiência dos tratamentos propostos, sendo $250 \mathrm{~mL}$ precipitados com hidróxido de sódio p.a. e outros $250 \mathrm{~mL}$ com sulfeto de sódio p.a. através da elevação gradual do $\mathrm{pH}$ sob leve agitação até próximo a 7, sendo constantemente monitorado durante este processo através de pHmetro com eletrodo de vidro Micronal B474. Foram consumidos 17 gramas de hidróxido de sódio p.a. até atingir pH 6,99 e 22 gramas de sulfeto de sódio atingindo pH 7,62.

As soluções resultantes foram decantadas por 24 horas e o sobrenadante foi analisado para determinação da taxa de remoção dos metais, bem como submetido à análise de mutagenicidade para A. cepa.

$\mathrm{O}$ teste de mutagenicidade foi realizado com bulbos selecionados sempre da mesma procedência. Cinco bulbos para cada tratamento foram colocados para germinar em água destilada três dias antes da exposição às amostras ou aos controles. Após este tempo, as raízes apresentavam de 3 a 5 $\mathrm{cm}$, em média, e a água destilada foi trocada pelas amostras e/ou controles.

As amostras de efluente foram aplicadas nas seguintes concentrações: $100 \%$ (bruto), $50 \%$ e $25 \%$. O controle negativo foi água destilada e o controle positivo foi trifluralina 0,84 ppm (Fernandes et al., 2007). O tempo de exposição foi de 24hs para as amostras de efluente e de 8 hs para a trifluralina. A trifluralina, empregada como controle positivo, é um conhecido pesticida classificado como possível carcinógeno humano (USEPA, 1993), tem efeito tóxico relativamente alto em organismos aquáticos (Chelme-Ayala et al., 2010) e promove danos causando descontrole na divisão celular.
Ao final deste tempo, todas as soluções foram novamente trocadas por água destilada por um período de 24 horas para recuperação, após o que as raízes foram cortadas próximas ao bulbo e colocadas num frasco com fixador Carnoy (álcool/ ácido acético 3:1) por 6 a 8 horas e em seguida transferidas para álcool $70 \%$ até o momento do preparo das lâminas.

Para o preparo das lâminas, as raízes foram submetidas a hidrólise em $\mathrm{HCl} 1 \mathrm{~N} \mathrm{a} 60^{\circ} \mathrm{C}$ por 10 minutos. Após este tempo, foram lavadas e imersas em reativo de Schiff, por 2 horas no escuro.

Sobre uma lâmina colocou-se um fragmento da raiz correspondente à região meristemática e sobre este, uma gota de carmim acético $2 \%$. O conjunto foi coberto com lamínula, pressionando-se suavemente. Outra lâmina foi confeccionada da mesma maneira, com a porção F1 da raiz (Fig. 1).

Foram contadas 500 células por lâmina em 10 lâminas por tratamento, em objetiva de 40X. O índice de aberrações cromossômicas (IAC) foi calculado da seguinte forma:

$$
I A C=\frac{\text { número de células alteradas }}{\text { total de células observadas }} \times 100
$$

O cálculo do índice de mutagenicidade (IM) seguiu a fórmula:

$$
I M=\frac{\text { número total de micronúcleos }}{\text { total de células observadas }} \times 100
$$

A análise estatística foi realizada através da comparação das médias encontradas para cada tratamento através do teste "t" de Student, com significância de $p \leq 0,05$.

\section{RESULTADOS}

Os resultados de $\mathrm{pH}$ e o volume mensal dos efluentes gerados na etapa de caracterização são indicados na Tabela 1.

Em relação aos metais, a Tabela 2 indica o valor mais baixo e o valor mais alto encontrado nos sete meses amostrados

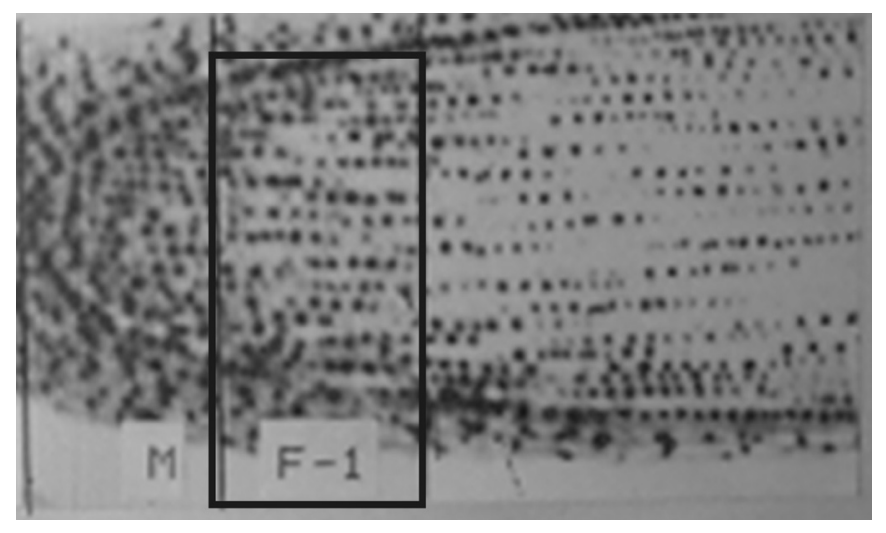

Fig. 1 - Seção longitudinal da raiz de Allium cepa: detalhe da obtenção da porção F1 da raiz. Fonte: Workshop on Plant Bioassays for the Detection of Mutagens and Carcinogens in the Environment", organizado pela SBMCTA - Brazilian Society of Environmental Mutagenesis, Carcinogenesis and Teratogenesis e Division Institute of Cancer Research of Medical University of Vienna. 
para cada um dos elementos analisados além dos seus limites máximos para descarte de acordo com o Art. 19-A do Decreto 8.468/76 (São Paulo/Br, 1976) e com o artigo 34 da Resolução Conama 357/2005 (alterado pela Resolução 430/2011).

Pode-se verificar que todos os elementos atingiram valores que exigem atenção, alguns deles ultrapassando $1000 \mathrm{mg} \mathrm{L}^{-1}$.

Os resultados dos metais antes e após precipitação com hidróxido de sódio e sulfeto de sódio podem ser observados na Tabela 3 .

Em relação à mutagenicidade, a figura 2 mostra uma comparação entre todos os resultados obtidos (amostra e controle positivo e negativo) no efluente bruto e após tratamento com hidróxido de sódio.

O tratamento com hidróxido de sódio reduziu significativamente $(\mathrm{p}<0,05)$ a porcentagem de micronúcleos nas três concentrações testadas. Apesar desta redução, a amostra permaneceu mutagênica, mesmo nas diluições testadas $(\mathrm{p}<0,05)$ em comparação ao controle negativo.

Tabela 1 - Determinação de pH e volume mensal dos efluentes gerados no período de sete meses

\begin{tabular}{lccccccc}
\hline & Mês & Mês & Mês & Mês & Mês & Mês & Mês \\
& 01 & 02 & 03 & 04 & 05 & 06 & 07 \\
\hline pH a $20^{\circ} \mathrm{C}$ & 0,10 & 0,05 & 0,02 & 0,02 & 0,05 & 0,04 & 0,10 \\
Volume (L) & 10,9 & 15,7 & 9,7 & 5,3 & 5,1 & 9,2 & 15,2 \\
\hline
\end{tabular}

Tabela 2 - Valor mínimo e máximo dos elementos e padrões para lançamento de efluentes segundo artigo 19-A do Decreto n ${ }^{\circ}$ 8.468/76 (SÃO PAULO, 1976) e Resolução Conama 430/2011 (BRASIL,2011).

\begin{tabular}{lcccc}
\hline Parâmetro & $\begin{array}{c}\text { Valor mínimo } \\
\text { encontrado } \\
\left(\mathrm{mg} \mathrm{L}^{-1}\right)\end{array}$ & $\begin{array}{c}\text { Valor } \\
\text { máximo } \\
\text { encontrado } \\
\left(\mathrm{mg} \mathrm{L}^{-1}\right)\end{array}$ & $\begin{array}{c}\text { VMP } \\
\left(\mathrm{mg} \mathrm{L}^{-1}\right)\end{array}$ & $\begin{array}{c}\text { VMP } \\
\left(\mathrm{mg} \mathrm{L}^{-1}\right)\end{array}$ \\
\hline $\mathrm{Ag}$ & 0,045 & 10,66 & 1,5 & 0,10 \\
$\mathrm{Cr}$ & 11,11 & 116,80 & 5,0 & Res.430/2011 \\
$\mathrm{Cu}$ & 8,77 & 356,50 & 1,5 & 1,0 \\
$\mathrm{Fe}$ & 387,40 & 1452 & 15,0 & 15,0 \\
$\mathrm{Ni}$ & 1,05 & 117,00 & 2,0 & 2,0 \\
$\mathrm{~Pb}$ & 0,74 & 9,15 & 1,5 & 0,5 \\
$\mathrm{Sn}$ & 1,97 & 25,90 & 4,0 & 4,0 \\
$\mathrm{Zn}$ & 362,70 & 4812 & 5,0 & 5,0 \\
\hline
\end{tabular}

Tabela 3 - Determinação de elementos metálicos antes e após precipitação com hidróxido de sódio e sulfeto de sódio no período de sete meses

\begin{tabular}{lccc}
\hline Parâmetro & $\begin{array}{c}\text { Antes da } \\
\text { precipitação } \\
\left(\mathrm{mg} \mathrm{L}^{-1}\right)\end{array}$ & $\begin{array}{c}\text { Após prec. com } \\
\text { hidróxido de } \\
\text { sódio }\left(\mathrm{mg} \mathrm{L}^{-1}\right)\end{array}$ & $\begin{array}{c}\text { Após prec. com } \\
\text { sulfeto de } \\
\text { sódio }\left(\mathrm{mg} \mathrm{L}^{-1}\right)\end{array}$ \\
\hline $\mathrm{Ag}$ & 1,09 & 0,84 & 0,015 \\
$\mathrm{Cr}$ & 33,24 & $<0,003$ & $<0,003$ \\
$\mathrm{Cu}$ & 104,10 & 0,069 & $<0,002$ \\
$\mathrm{Fe}$ & 885 & 0,15 & 0,15 \\
$\mathrm{Ni}$ & 13,00 & $<0,081$ & 0,59 \\
$\mathrm{~Pb}$ & 4,03 & $<0,020$ & $<0,020$ \\
$\mathrm{Sn}$ & 0,84 & $<0,009$ & 0,39 \\
$\mathrm{Zn}$ & 434,40 & 2,90 & 1,33 \\
\hline
\end{tabular}

A Fig. 3 mostra uma comparação entre todos os resultados obtidos (amostra e controle positivo e negativo) no efluente bruto e após tratamento com sulfeto de sódio.

O tratamento com sulfeto de sódio promoveu redução significante da porcentagem de micronúcleos na amostra a $100 \%$ e a $50 \%(p<0,05)$, mas não a $25 \%$. Apesar da redução, aqui também as amostras permaneceram mutagênicas em relação ao controle negativo.

\section{DISCUSSÃO}

Plantas superiores apresentam características que as tornam excelentes modelos genéticos para avaliar a contaminação ambiental. Atualmente, entre as espécies de plantas mais utilizadas para avaliar a contaminação ambiental, as mais frequentes são Allium cepa, Vicia faba e Zea mays, Tradescantia sp., Nicotiana tabacum, Capillaris crepis e Hordeum vulgare (Grant, 1994). Entre essas espécies, A. cepa tem sido considerada favorável para avaliar os danos

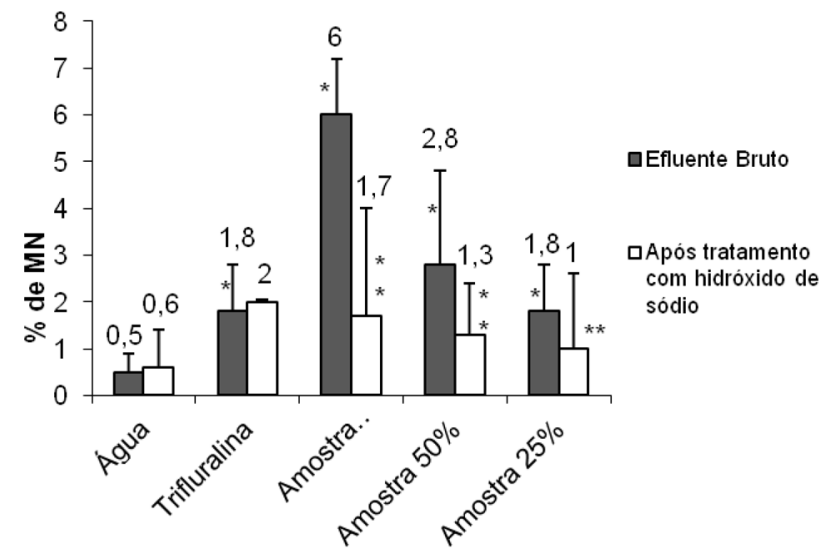

Fig. 2 - Produção de micronúcleos em Allium cepa antes e após tratamento com hidróxido de sódio no período de sete meses. * valor do tratamento estatisticamente significante $(\mathrm{p}<0,05)$ em relação ao controle negativo. *** valores estatisticamente significantes $(p<0,05)$ em relação ao tratamento com $\mathrm{NaOH}$. As barras sobre as colunas se referem ao desvio-padrão.

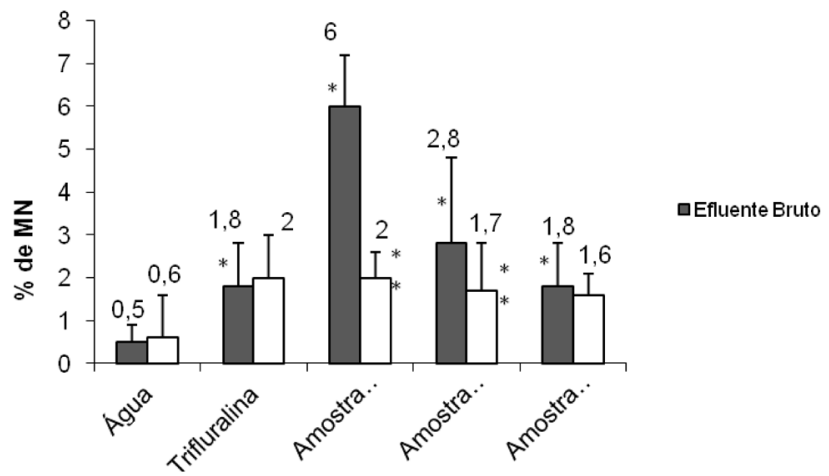

Fig. 3 - Produção de micronúcleos em Allium cepa antes e após tratamento com sulfeto de sódio no período de sete meses. * valor do tratamento estatisticamente significante $(\mathrm{p}<0,05)$ em relação ao controle negativo. ** valores estatisticamente significantes $(p<0,05)$ em relação ao tratamento com $\mathrm{Na}_{2} \mathrm{~S}$. As barras sobre as colunas se referem ao desvio-padrão. 
cromossômicos e distúrbios no ciclo mitótico, devido à presença de cromossomos grandes e em número reduzido $(2 n=16)$ (Fiskesjö, 1985). Além disso, este sistema de teste demonstrou elevada sensibilidade na detecção de agentes químicos (Leme \& Marin-Moralles, 2009). O teste de A. cepa tem sido considerado por muitos autores, como um ensaio de baixo custo e de fácil manuseio, que apresenta algumas vantagens sobre outros testes de curto prazo utilizados no monitoramento ambiental (Rank \& Nielsen, 1998; Rank, 2003; Fatima \& Ahmad, 2006).

De acordo com Rank \& Nielsen (1998) e Rank (2003), outra vantagem do teste de $A$. cepa é a possibilidade de expor o organismo e testar diretamente misturas complexas sem tratamento prévio da amostra. Para Ma et al. (1995), entre todos os pontos finais avaliados, o micronúcleo (MN) é o indicador mais eficaz e simples de danos citológicos, o que torna a análise deste parâmetro mais eficiente para avaliar a contaminação ambiental. Além disso, o tamanho do MN pode ser um parâmetro eficaz para avaliar os efeitos clastogênicos e aneugênicos em $A$. cepa, uma vez que esta espécie apresenta um cariótipo simétrico, que é homogêneo em relação ao tamanho cromossômico, com cromossomos grandes e poucos. Portanto, um MN grande poderia indicar um efeito aneugênico, resultante de uma perda de cromossomos, enquanto que um MN pequeno pode indicar uma ação clastogênica, resultante da quebra cromossômica (Leme et al., 2008).

Ao comparar a atividade mutagênica do efluente bruto com o mesmo efluente após os tratamentos para precipitação de íons metálicos, houve estatisticamente significante redução do efeito após tratamento, porém os índices de mutagenicidade avaliados por meio da quantificação da presença de micronúcleos em células de Allium cepa mostram que o efluente em estudo após o tratamento, mesmo diluído apresentou atividade mutagênica que foi significativamente maior que a do controle negativo com água. A redução da toxicidade também foi evidenciada com o uso de ambos os reagentes nas três concentrações consideradas. No entanto, foi considerado vantajoso o tratamento com hidróxido de sódio $(\mathrm{NaOH})$, em decorrência dos efeitos residuais do sulfeto, no tratamento com sulfeto de sódio $\left(\mathrm{Na}_{2} \mathrm{~S}\right)$.

Em trabalho de Silva et al. (2009), foi observada significante redução da atividade mutagênica do efluente industrial de uma indústria metalúrgica após o seu tratamento com EDTA, conforme recomendação do procedimento TIE (Toxicity Identity Evaluation) - Fase I USEPA. Também foi observada significante redução da toxicidade subcrônica em algas, após a remoção de metais pelo tratamento de efluentes em diferentes localidades dos EUA (Butler et al., 2011). Em conjunto, estes dados corroboram a importante contribuição dos elementos metálicos no efeito tóxico (Magdaleno et al., 2008; Villatoro-Pulido et al., 2008; Asakura et al., 2009; Yadav \& Trivedi, 2009).

Desta forma, o monitoramento biológico através da utilização de ensaios ecotoxicológicos torna-se um importante instrumento na avaliação da toxicidade de um efluente, pois ao contrário dos ensaios químicos e físico-quimicos, que avaliam pontualmente determinados parâmetros, os ensaios ecotoxicológicos são capazes de estimar não apenas as potencialidades individuais, mas também as da mistura destes constituintes (Bertoletti, 1990).

A legislação vigente no Brasil, isto é, a Resolução CONAMA 357/05 (Brasil, 2005), alterada pela Resolução Conama 430/2011 (Brasil, 2011) além de estabelecer os padrões de qualidade das águas continentais, estuarinas e marinhas, bem como a classificação e os usos preponderantes das águas superficiais, também regulamenta o lançamento de efluentes em corpos de água. Printes (2000) sugeriu a inclusão de parâmetros biológicos associados aos parâmetros físico-químicos ao fazer uma análise crítica da classificação brasileira de qualidade das águas estabelecidas por esta Resolução. Bassoi et al. (1990) apontam que o monitoramento biológico complementa os procedimentos já adotados através do monitoramento químico. Em testes realizados com efluentes tóxicos, Sponza $(2002 ; 2006)$ e Barata et al. (2008) concluíram que os resultados de toxicidade obtidos enfatizam a necessidade de incluir testes deste tipo para monitorar mais realisticamente a toxicidade de efluentes ou águas superficiais que recebem descarte de efluentes. Outros autores também já ressaltaram a importância da realização de ambos os tipos de monitoramento para uma completa avaliação dos efeitos resultantes das atividades humanas sobre o meio ambiente (Fowler \& Aguiar, 1991; Ravera, 1998; Van der Velde \& Leuven, 1999).

Finalmente, do ponto de vista físico-químico, pode-se verificar que os efluentes analisados apresentaram $\mathrm{pH}$ muito abaixo do limite definido pelo artigo 19-A do Decreto $\mathrm{n}^{0}$ 8468/76 (São Paulo/BR, 1976) (que estabelece valor mínimo de 6) e pelo artigo 16 da Resolução Conama 430/2011 (Brasil, 2011) (que estabelece valor mínimo de 5) para descarte e, que o volume médio produzido pelo laboratório foi $10,2 \mathrm{~L}$, isto é um pequeno volume se comparado a uma planta industrial.

Os resultados deste trabalho evidenciam a necessidade de um controle mais abrangente do tratamento de efluentes, uma vez que mesmo estando apto para descarte de acordo com a legislação, ficou evidente o fato do efluente em estudo permanecer com potencial mutagênico mesmo após os tratamentos aplicados. Além disso, o efluente em estudo, após tratamento por precipitação química tornou-se apto para descarte de acordo com o Decreto $n^{\circ}$ 8468/76 (São Paulo/ BR, 1976), considerando os elementos metálicos pesquisados apresentando inclusive, teores abaixo dos especificados em norma para alguns elementos. Os dados também corroboram com a importante contribuição dos metais no efeito mutagênico do efluente, conforme observada pela significante redução do efeito tóxico após o tratamento. Contudo, apesar desta redução, o efluente permaneceu mutagênico no teste com $A$. сера, mesmo após tratamento.

Este trabalho se soma a outros (Kim et al., 2008; Butler et al., 2011; Sancey et al., 2011) que chamam a atenção para a contribuição de bioensaios como o aqui realizado, no monitoramento controle das descargas de efluentes e, portanto, como adjuvantes junto à legislação vigente, especialmente no que se refere à contaminação por metais. 


\section{REFERÊNCIAS}

ABO-FARHA, S. A.; ABDEL-AAL, A. Y.; ASHOUR I. A. \& GARAMON, S. E., 2009, Removal of some heavy metal cations by synthetic resin purolite C100. J. Haz. Mat., 169: 190-194. http://dx.doi.org/10.1016/j.jhazmat.2009.03.086.

ASAKURA, K.; SATOH, H.; CHIBA, M.; OKAMOTO, M.; SERIZAWA, K.; NAKANO, M. \& OMAE, K., 2009, Genotoxicity studies of heavy metals: lead, bismuth, indium, silver and antimony. J. Occup. Health, 51: 498-512. http://dx.doi. org/10.1539/joh.L9080.

BAGATINI, M. D.; VASCONCELOS, T. G.; LAUGHINGHOUSE, H. D.; MARTINS, A. F. \& TEDESCO, S. B., 2009, Biomonitoring Hospital Effluents by the Allium cepa L. Test. Bull Environ. Contam. Toxicol., 82: 590-592. http://dx.doi.org/10.1007/ s00128-009-9666-z.

BARATA, C.; ALAÑON, P.; GUTIERREZ-ALONSO, S.; RIVA, M. C.; FERNÁNDEZ, C. \& TARAZONAC, J. V., 2008, A Daphnia magna feeding bioassay as a cost effective and

ecological relevant sublethal toxicity test for Environmental Risk Assessment of toxic effluents. Sci. Total Environ. 405: 78-86. http://dx.doi.org/10.1016/j.scitotenv.2008.06.028.

BASSOI, L. J.; NIETO, R. \& TREMAROLI, D., 1990, Implementação de Testes de Toxicidade no Controle de Efluentes Líquidos. CETESB, São Paulo.

BERTOLETTI, E., 1990, Toxicidade e concentração de agentes tóxicos em efluentes industriais. Cienc. Cult., 42: 271-277.

BRASIL, 2005. Ministério do Meio Ambiente. Resolução $n^{\circ} 357$ do CONAMA, Brasília, DF.

BRASIL, 2011. Ministério do Meio Ambiente. Resolução nº 430 do CONAMA, Brasília, DF.

BUTLER, B. A.; SMITH, M. E.; REISMAN, D. J. \& LAZORCHAK, J. M., 2011, Metal removal efficiency and ecotoxicological assessment of field-scale passive treatment biochemical reactors. Environ. Toxicol. Chem., 30: 385-392. http://dx.doi.org/10.1002/ etc. 397.

CHATTERJEE, S. K.; BHATTACHARJEE, I. \& CHANDRA, G., 2010, Biosorption of heavy metals from industrial waste water by Geobacillus thermodenitrificans. J. Haz. Mat. 175: 117-125. http://dx.doi.org/10.1016/j.jhazmat.2009.09.136.

CHELME-AYALA, P.; EL-DIN, M. G. \& SMITH, D. W., 2010, Degradation of bromoxynil and trifluralin in natural water by direct photolysis and UV plus $\mathrm{H}_{2} \mathrm{O}_{2}$ advanced oxidation process. Wat.Research, 44: 2221-2228. http://dx.doi.org/10.1016/j. watres.2009.12.045.

DIZER, H.; WITTEKIND, E.; FISCHER, B. \& HANSEN, P. D., 2002, The cytotoxic and genotoxic potential of surface water and wastewater effluents determined by bioluminescence, umuassays and selected biomarkers. Chemosphere, 46: 225-233. http://dx.doi.org/10.1016/S0045-6535(01)00062-5.

EATON, A. D.; CLESCERI, L. S.; RICE, E. W.; GREENBERG, A. E. \& FRANSON, M. A. H. , 2005, Standard methods for the examination of water and wastewater, 21 ed. American Public Health Association, American Water Works Association, Water Environment Federation, Washington, D. C.

EL-SHAHABY, O. A.; ABDEL MIGID, H. M.; SOLIMAN, M. I. \& MASHALY, I. A., 2003, Genotoxicity screening of industrial wastewater using the Allium cepa chromosome aberration assay. Pak. J. Biol. Sci., 6: 23-28. http://dx.doi.org/10.3923/ pjbs.2003.23.28.

FATIMA, R. A. \& AHMAD, M., 2006, Genotoxicity of industrial wastewaters obtained from two different pollution sources in northern India: a comparison of three bioassays. Mutat. Res., 609: 81-91. http://dx.doi.org/10.1016/j.mrgentox.2006.06.023.
FERNANDES, T.C.C.; MAZZEO,D.E.C.; MARIN-MORALES, M. A., 2007, Mechanism of micronuclei formation in polyploidizated cells of Allium cepa exposed to trifluralin herbicide. Pesticide Biochemistry and Physiology, v. 88, p. 252-259. http://dx.doi. org/10.1016/j.pestbp.2006.12.003.

FISKESJÖ, G., 1985, The Allium test as a standard in the environmental monitoring. Hereditas, 102: 99-112. http://dx.doi. org /10.1111/j.1601-5223.1985.tb00471.x.

FISKESJÖ, G., 1993, The Allium test in Wastewater monitoring. Environ. Toxicol. Water Qual, 8: 291-298. http://dx.doi.org /10.1002/tox. 2530080306 .

FOWLER, H. G. \& AGUIAR, A. M., 1991, A integração da teoria ecológica na análise ambiental. In: S. M. TAUK; N. GOBBI \& H.G. FOWLER (Org.) Análise Ambiental: uma visão multidisciplinar. Editora UNESP, São Paulo.

FRANCHI, J. G., 2004, A utilização de turfa como adsorvente de metais pesados. O exemplo da contaminação da bacia do rio Ribeira de Iguape por chumbo e metais associados, Tese (Doutorado, Instituto de Geociências) - Universidade de São Paulo, São Paulo.

GABALLAH, I. \& KILBERTUS, G., 1998, Recovery of heavy metal ions through decontamination of synthetic solutions and industrial effluents using modified barks. J. Geochem. Explor., 62: 241286. http://dx.doi.org/10.1016/S0375-6742(97)00068-X.

GHERARDI-GOLDSTEIN, E.; BERTOLETTI, E.; ZAGATTO, P. A.; ARAÚJO, R. P. A. \& RAMOS, M. L. L. C., 1990, Procedimentos para Utilização de Testes de Toxicidade no Controle de Efluentes Líquidos. CETESB, São Paulo.

GRANT, W. F., 1994, The present status of higher plant bioassays for detection of environmental mutagens. Mut. Res., 310: 175185. http://dx.doi.org/10.1016/0027-5107(94)90112-0.

HUISMAN, J. L.; SCHOUTEN, G. \& SCHULTZ. C., 2006, Biologically produced sulphide for purification of process streams, effluent treatment and recovery of metals in the metal and mining industry. Hydrometallurgy, 83: 106-113. http:// dx.doi.org/10.1016/j.hydromet.2006.03.017.

JANIN, A.; ZAVISKA, F.; DROGUI, P.; BLAIS, J.-F. \& MERCIER, G., 2009, Selective recovery of metals in leachate from chromated copper arsenate treated wastes using electrochemical technology and chemical precipitation. Hydrometallurgy, 96: 318-326.

http://dx.doi.org/10.1016/j.hydromet.2008.12.002.

KIM, E.; JUN, Y. R.; JO, H. J.; SHIM, S. B. \& JUNG, J., 2008, Toxicity identification in metal plating effluent: implications in establishing effluent discharge limits using bioassays in Korea. Mar. Pollut. Bull., 57: 637-44. http://dx.doi.org/10.1016/j. marpolbul.2008.02.042.

KRAMER, J. R. \& ALLEN, H. E., 1988, Metal Speciation - Theory, analysis and application. Lewis Publishers, Chelsea, 357p.

LEME, D. M.; ANGELIS, D. F. \& MARIN-MORALES, M. A., 2008, Action mechanisms of petroleum hydrocarbons present in waters impacted by an oil spill on the genetic material of

Allium cepa root cells. Aquat. Toxicol., 88: 214-219. http://dx.doi. org/10.1016/j.aquatox.2008.04.012.

LEME, D. M. \& MARIN-MORALES, M. A., 2009, Allium cepa test in environmental monitoring: A review on its application. Mut. Res. 682: 71-81. http://dx.doi.org/10.1016/j.mrrev.2009.06.002.

LÉON, V.; RABIER, J.; NOTONIER, R.; BARTHELÉMY, R.; MOREAU, X.; BOURAÏMA-MADJÈBI, S.; VIANO, J. \& PINEAU, R., 2005, Effects of three nickel salts on germinating seeds of Grevillea exul var. rubiginosa, an endemic serpentine Proteaceae. Ann. Bot., 95: 609-618. http://dx.doi.org/10.1093/ aob/mci066.

LIN, S. H. \& JUANG, R. S., 2002, Heavy metal removal from water by sorption using surfactant-modified montmorillonite. 
J. Haz. Mat., 92: 315-326. http://dx.doi.org/10.1016/S03043894(02)00026-2.

MA, T. H.; XU, Z.; XU, C.; McCONNELL, H.; RABAGO, E. V.; ARREOLA, G. A. \& ZHANG, H., 1995, The improved Allium/Vicia root tip micronucleus assay for clastogenicity of environmental pollutants. Mut. Res., 334: 185-195. http://dx.doi. org/10.1016/0165-1161(95)90010-1.

MAGDALENO, A.; MENDELSON, A.; De IORIO, A. F.; RENDINA, A. \& MORETTON, J., 2008, Genotoxicity of leachates from highly polluted lowland river sediments destined for disposal in landfill. Waste Man., 28: 2134-2139. http://dx.doi. org/10.1016/j.wasman.2007.09.027.

MATSUMOTO, S. T.; MANTOVANI, M. S.; MALAGUTTII, M. I. A.; DIAS, A. L.; FONSECA, I. C. \& MARIN-MORALES, M. A., 2006, Genotoxicity and mutagenicity of water contaminated with tannery effluents, as evaluated by the micronucleus test and comet assay using the fish Oreochromis niloticus and chromosome aberrations in onion root-tips. Gen. Mol. Biol., 29: 148-158. http://dx.doi.org/10.1590/S1415-47572006000100028.

MAZZEO, D. E.; LEVY, C. E.; DE ANGELIS, D. de F. \& MARINMORALES, M. A., 2010, BTEX biodegradation by bacteria from effluents of petroleum refinery. Sci. Total Environ., 408: 4334-40. http://dx.doi.org/10.1016/j.scitotenv.2010.07.004.

NASCIMENTO, S. C.; HYPOLITO, R. \& RIBEIRO, A. A., 2006, Disponibilidade de metais pesados em aterro de indústria siderúrgica. Eng. Sanit. Amb., 11: 196-202. http://dx.doi. org/10.1590/S1413-41522006000300002.

PESSALA, P.; SCHULTZ, E.; NAKARI, T.; JOUTTI, A. \& HERVE, S., 2004, Evaluation of wastewater effluents by small-scalle biotests and a fractionation procedure. Ecot. Environ. Safety, 59: 263-272. http://dx.doi.org/10.1016/j.ecoenv.2003.10.002.

PRINTES, L. B., 2000, The Brazilian classification scheme for water quality and protection of aquatic communities: the need for improvement. (Thesis Master of Science in Biodiversity Management) - University of Kent, Canterbury.

RADIĆ, S.; STIPANIČEV, D.; VUJČIĆ, V.; RAJČIĆ, M. M.; ŠIRAC, S. \& PEVALEK-KOZLINA, B., 2010, The evaluation of surface and wastewater genotoxicity using the Allium cepa test. Sci. Total Environ. 408: 1228-1233. http://dx.doi.org/10.1016/j. scitotenv.2009.11.055.

RANK, J., 2003, The method of Allium anaphase-telophase chromosome aberration assay.

Ekologija, 1: 38-42.

RANK, J.; NIELSEN, M. H. Genotoxicity testing of wastewater sludge using the Allium cepa anaphase-telophase chromosome aberration assay. Mut. Res, v. 418, p. 113-119, 1998.

http://dx.doi.org/10.1016/S1383-5718(98)00118-1.

RAVERA, O., 1998, Utility and limits of biological and chemical monitoring of the aquatic environment. Annali di Chimica, 88: 909-913.
RAYA-RODRIGUEZ, M. T., 2000, O uso de bioindicadores para avaliação da qualidade do ar em Porto Alegre. In: M. L. L. ZURITA \& TOLFO, A.M. (Org.) A Qualidade do Ar em Porto Alegre. Secretaria Municipal do Meio Ambiente, Porto Alegre.

SANCEY, B.; TRUNFIO, G.; CHARLES, J.; MINARY, J. F.; GAVOILLE, S.; BADOT, P. M. \& CRINI, G., 2011, Heavy metal removal from industrial effluents by sorption on crosslinked starch: chemical study and impact on water toxicity. J. Environ. Manage., 92:765-772.

http://dx.doi.org/10.1016/j.jenvman.2010.10.033.

SÃO PAULO/BR, 1976, Decreto nº 8468, São Paulo.

SILVA, L. F., BREGAGNOLO, L., SOUZA, C. C. \& IRAZUSTA, S. P., 2009, Mutagenicidade do efluente de uma indústria metalúrgica - Sorocaba - Aplicação do TIE (Fase 1). XI Simpósio de Iniciação Científica da Faculdade de Tecnologia de São Paulo (FATEC), São Paulo.

SPONZA, D.T., 2002, Necessity of toxicity assessment in Turkish industrial discharges (examples from metal and textile industry effluents). Environ. Monit. Assess., 73: 41-66.

http://dx.doi.org/10.1023/A:1012663213153.

SPONZA, D. T., 2006, Incorporation of Toxicity Tests into the Turkish Industrial Discharge

Monitoring Systems. Arch. Environ. Contam. Toxicol., 43: 186-197. http://dx.doi.org/10.1007/s00244-002-1150-2.

USEPA - UNITED STATES ENVIRONMENTAL PROTECTION AGENCY, 1993, Trifluralin. Disponível em: <http://www.epa. gov/NCEA/iris/subst/0268.htm> Acesso em: 22/04/2010.

VAN DER VELDE, G. \& LEUVEN, R. S. E. W., 1999, Polluted river systems: monitoring and assessment of ecotoxicological risks. Acta Hydrochim. Hydrobiol., 27: 251-256.

http://dx.doi.org $/ 10.1002 /(\mathrm{SICI}) 1521$ 401X(199911)27:5<251::AID-AHEH251>3.0.CO;2-I.

VILLATORO-PULIDO, M.; FONT, R.; De HARO-BRAVO, M. I.; ROMERO-JIMÉNEZ, M.; ANTER, J.; De HARO BAILÓN, A.; ALONSO-MORAGA, A. \& Del RÍO-CELESTINO, M., 2008, Modulation of genotoxicity and cytotoxicity by radish grown in metal-contaminated soils. Mutagenesis, 24: 51-57. http://dx.doi. org/10.1093/mutage/gen051.

YADAV, K. K. \& TRIVEDI, S. P., 2009, Chromosomal aberrations in a fish, Channa punctata after in vivo exposure to three heavy metals. Mut. Res., 678: 7-12.

http://dx.doi.org/10.1016/j.mrgentox.2009.05.021.

WANG J. \& CHEN, C. 2009, Biosorbents for heavy metals removal and their future. Biotechnol. Adv., 27: 195-226. http://dx.doi. org/10.1016/j.biotechadv.2008.11.002.

ZAKI, N. G.; KHATTAB, I. A. \& ABD EL-MONEM, N. M., 2007, Removal of some heavy metals by CKD leachate. J. Haz. Mat., 147: 21-27. http://dx.doi.org/10.1016/j.jhazmat.2006.12.057. 